\title{
PENGEMBANGAN MEDIA PEMBELAJARAN CARA MEMBUAT PERMAINAN VIDEO PADA GENRE TURN BASED ADVENTURE RPG DI SMKN 6 JAKARTA
}

\author{
Abhy Sukma Pratama ${ }^{1}$, Bambang Prasetya A. ${ }^{2}$, Prasetyo Wibowo Y. ${ }^{3}$ \\ 1,2,3 Abhy Sukma P., Bambang Prasetya A., Prasetyo Wibowo Y., Teknik Elektro, FT - UNJ \\ 1abhyniwa@yahoo.co.id, ${ }^{2}$ bambangpadhi@unj.ac.id, ${ }^{3}$ prasetyo.wy@unj.ac.id
}

\begin{abstract}
Abstrak
Di SMKN 6 terdapat banyak murid yang tidak bisa membuat permainan video dan membuat presentasi video yang baik dan benar. Penelitian ini bertujuan untuk mengembangkan media pembelajaran berbentuk video tutorial yang dapat memberikan contoh presentasi video yang baik dan benar serta mengenalkan murid cara untuk membuat permainan video Turn Based Adventure RPG. Penelitian ini mengunakan metode pengembangan RnD yang dikembangkan oleh Sugiyono dengan langkah pengumpulan informasi, mendesain produk, uji ahli, revisi desain, dan uji produk. Pada fase pengujian, media di uji oleh ahli media dan ahli materi masing masing 3 ahli. Pada fase implementasi, media di uji efektifitas oleh 30 murid SMKN 6 kelas 10 MM sebagai responden. Sebelum instrumen digunakan, instrumen divalidasi terlebih dahulu. Hasil uji efektifitas adalah video mendapatkan persentase total $91 \%$ dalam memberikan siswa pemahaman membuat permainan video. Hasil uji angket siswa memiliki skor total rata rata 90. Sehingga dapat disimpulkan bahwa video sangat bagus dalam kualitas sosial aspek dampak bagi siswa, kualitas teknik aspek kualitas tampilan, kualitas isi aspek ketepatan, kualitas pembelajaran aspek minat dan perhatian, dan kualitas isi aspek ketepatan.
\end{abstract}

Kata kunci : Permainan Video, Turn Based Adventure RPG, Presentasi Video, Media Pembelajaran

\section{Pendahuluan}

Sekolah Menengah Kejuruan (SMK) adalah sekolah yang bertujuan untuk mempersiapkan peserta didiknya agar dapat bekerja pada bidang tertentu. Dalam mencapai tujuan tersebut peserta didik berinteraksi dengan lingkungan belajar yang diatur guru memalui proses pembelajaran. Dalam proses pembelajaran, media memiliki fungsi sebagai pembawa informasi dari sumber (guru) menuju penerima (siswa). Sedangkan metode adalah prosedur untuk membantu siswa dalam menerima dan mengolah informasi guna mencapai tujuan pembelajaran (Muhammad Anas, 2014: 12). Dengan kata lain, yang menentukan murid dalam mengerti pelajaran dalam kegiatan belajar mengajar adalah metode mengajar dan medianya.

Di SMK Negeri 6 Jakarta pada program keahlian multimedia dan program keahlian animasi terdapat mata pelajaran yaitu permainan edukasi tujuan mata pelajaran ini agar siswa dapat mengetahui tentang permainan dan dapat membuat permainan edukasi dan pelajaran simulasi digital yang salah satu materinya presentasi video yang bertujuan agar siswa mengetahui cara presentasi video yang baik dan benar.

Berdasarkan observasi lapangan di SMK Negeri 6 Jakarta kelas 10 Multimedia dengan jumlah 33 siswa pada proses pembelajaran mata pelajaran simulasi digital, materi presentasi video banyak murid yang belum bagus memberikan contoh presentasi video yang baik dan benar. Penyebabnya antara lain murid belum mendapat contoh presentasi video yang baik dan benar.

Selain itu, belum tersedianya media pembelajaran yang sesuai dengan kompetensi mata pelajaran presentasi video di SMK Negeri 6 Jakarta. Media video yang ada di internet kurang sesuai dengan kompetensi mata pelajaran. Hal ini membuat siswa kesulitan untuk memahami media pembelajaran yang ada.

Di SMK 6 Jakarta kelas 12 terdapat pelajaran Game Edukasi dimana siswa nantinya diharapkan untuk dapat membuat permainan video edukasi sendiri. Namun, ternyata banyak siswa kelas 12 yang belum mengerti cara membuat permainan video edukasi. Hal ini dikarenakan kurangnya video yang dapat membantu siswa membuat permainan video. Kelas 11 SMK Multimedia mempunyai lomba kreatifitas siswa yang salah satu isi lomba nya adalah membuat permainan video, namun siswa belum dapat pelajaran membuat permainan video dari kelas 10, hal ini membuat guru yang mengajarkan materi pun mengusulkan kepada penulis agar membuat video tutorial cara membuat permainan yang nantinya di tampilkan sebagai contoh presentasi video yang baik dan benar pada pelajaran simulasi digital kelas 10 dengan harapan video tersebut juga dapat memperkenalkan siswa cara membuat permainan video. Guru juga mengusulkan agar video tutorial mengajarkan cara 
membuat permainan video bergenre Turn Based Adventure RPG. Hal ini dikarenakan video bahasa Indonesia yang mengajarkan cara membuat Turn Based Adventure RPG sangat sedikit padahal genre Turn Based Adventure RPG mempunyai banyak peminat.

Penggunaan media pembelajaran video tutorial akan membantu dan mempermudah proses pembelajaran untuk siswa maupun guru siswa dapat belajar lebih dahulu dengan melihat dan menyerap materi belajar. Dengan demikian proses pembelajaran dapat berlangsung lebih menarik, efisien dan efektif. Video tutorial akan menjadi media pembelajaran yang menarik dan dapat menyampaikan informasi secara lengkap serta jelas.

Berdasarkan permasalahan ini penulis ingin membuat suatu video tutorial membuat permainan yang banyak peminat nya, yaitu Turn Based Adventure RPG. Sehingga penulis akan membuat penelitian yang bertujuan untuk mengajarkan cara pembuatan permainan video Turn Based Adventure RPG dan juga memberikan contoh presentasi video yang baik dan benar dengan harapan video tersebut juga dapat mengenalkan murid cara membuat permainan video Turn Based Adventure RPG dan membantu meningkatkan kinerja murid untuk membuat permainan video.

\section{Dasar Teori}

Research and Development adalah metode penelitian yang digunakan untuk menghasilkan produk tertentu dan menguji keefektifan produk tersebut (Sugiyono, 2017:297). Menurut Sugiyono (2017:298-310) menjelaskan bahwa secara umum langkah - langkah dalam penelitian dan pengembangan terdapat sepuluh tahapan.

Potensi masalah, pada tahap ini masalah diidentifikasi dimana harus merupakan sesuatu yang sesuai dengan data empirik yang bisa berdasarkan laporan penelitian orang lain, atau dokumentasi laporan penelitian orang lain, atau dokumentasi laporan instansi yang terbaru .

Pengumpulan data, setelah masalah dapat ditunjukkan secara faktual dan terbaru, maka pada tahap ini bertugas mengumpulkan berbagai data dan informasi yang digunakan sebagai perencanaan produk tertentu yang diharapkan dapat mengatasi masalah tersebut.

Desain produk, pada tahap ini, desain produk dapat diwujudkan dalam bentuk gambar atau bagan, sehingga dapat digunakan sebagai pegangan untuk menilai dan membuatnya.

Validasi desain, pada tahap ini merupakan kegiatan untuk menilai rancangan produk menjadi lebih efektif dibanding versi sebelumnya. Penilaian dapat dilakukan dengan cara mendatangkan para ahli yang sudah berpengalaman dibidangnya untuk menilai produk tersebut sehingga selanjutnya diketahui kelemahan dan kekuatannya.
Revisi desain, pada tahap ini dilakukan setelah diketahui kelemahan dari produk tersebut dilakukan percobaan untuk perbaikan desain.

Uji coba produk, pada tahap ini dilakukan uji coba produk tahap awal dilakukan dengan simulasi penggunaan produk tersebut kepada kelompok terbatas.

Revisi produk, pada tahap ini dilakukan untuk menemukan kelemahan dan kekurangan produk yang dikembangkan setelah dilakukan uji coba pada kelompok terbatas.

Uji coba pemakaian, pada tahap ini dilakukan setelah revisi produk tersebut diterapkan pada kelompok yang lebih luas.

Revisi produk, pada Tahap ini merupakan revisi produk akhir, dimana apabila dalam pemakaian produk yang lebih luas masih terdapat kekurangan maka harus dievaluasi dan disempurnakan kembali.

Pembuatan produk si Massal Pada tahap ini merupakan tahapan akhir dari penelitian R\&D dimana produk sudah siap di publikasikan.

Menurut Borg and Gall (1989: 624), educational research and development is a process used to develop and validate educational product, artinya bahwa penelitian pengembangan pendidikan (R\&D) adalah sebuah proses yang digunakan untuk mengembangkan dan memvalidasi produk Pendidikan

Lebih lanjut Borg and Gall (dalam Sugiyono, 2017: 11) menyatakan bahwa untuk penelitian analisis kebutuhan sehingga mampu dihasilkan produk.

Menurut Miarso dalam Indriana (2011:14) berpendapat bahwa media merupakan segala sesuatu yang dapat digunakan untuk menyalurkan pesan yang dapa merangsang pikiran, perasaan, perhatian, dan kemauan siswa untuk belajar.

Cecep Kustandi (2013: 64) mengungkapkan bahwa video adalah alat yang dapat menyajikan informasi, memaparkan proses, menjelaskan konsepkonsep yang rumit, mengajarkan keterampilan, menyingkat atau memperlambat waktu dan mempengaruhi sikap.

\section{Metodologi}

Menurut Depdiknas (2004) dalam buku Andi (2014: 353-354) ada beberapa langkah yang dilakukan dalam mengembangkan video tutorial, dimana semuanya dilakukan secara bertahap dan sistematis.

Rancangan Media Pembelajaran Presentasi Video di bagi beberapa tahap sesuai dengan penyederhanaan metode R\&D Sugiyono, berikut penjelasan dari tahap-tahap yang dilakukan dalam proses pembuatan video tutorial cara membuat permainan video RPG Turn Based. Tahap pengumpulan data dan infromasi, meliputi: pengumpulan data kemampuan murid, kemampuan guru dalam mengajar dengan observasi. Tahap 
desain Media Pembelajaran Presentasi Video, meliputi: memikirkan konsep permainan video yang akan dibuat dan memikirkan bagaimana alur video tutorial. Kemudian mendesain storyboard video tutorial dan permainan video lalu menyiapkan peralatan untuk membuat video dan permainan video. Setelah itu membuat permainan video, setelah permainan video dibuat, maka proses selanjutnya adalah merekam pembuatan permainan video ulang sebagai isi dari video tutorial. Validasi tim ahli, meliputi: memvalidasi instrumen yang akan digunakan untuk menguji Media Pembelajaran Presentasi Video dan memberikan video tutorial kepada tim ahli untuk dinilai apakah video tersebut layak atau tidak. Revisi desain, meliputi: merevisi video dan angket bila menurut tim ahli masih ada kriteria yang belum layak. Uji coba Media Pembelajaran Presentasi Video, meliputi pengetesan video dengan cara memberikan video yang telah di validasi oleh ahli dan mempunyai semua kriteria layak menurut ahli kepada murid lalu dinilai seberapa efektif video tersebut dalam mengajar murid.

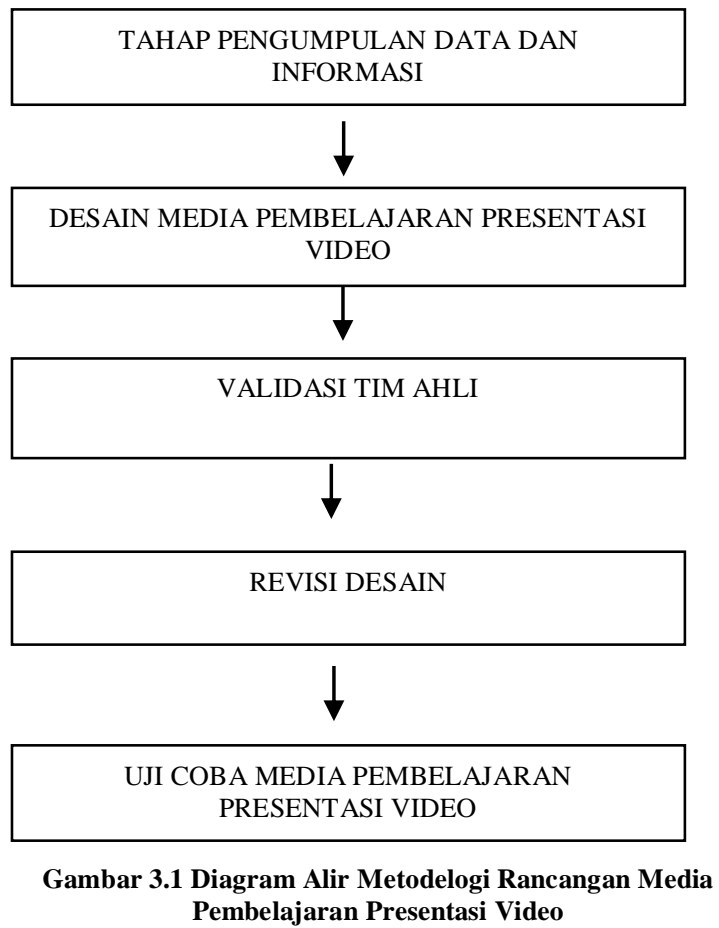

\section{Hasil dan Analisis}

Hasil perhitungan kelayakan video tutorial bedasarkan tes formatif menggunakan rumus Sugiyono. Aspek respon siswa terhadap isi materi pada indikator mengerti cara membuat script yang dapat mengganti scene mendapat skor 2800 dari 3000 atau jika dalam persentase sebesar 93,33\%. Selanjutnya, pada indikator kedua yaitu mengerti cara membuat cara membuat musuh mendekati player mendapat skor 2700 dari 3000 atau jika dalam persentase sebesar $90,00 \%$. Dan indikator yang terakhir yaitu mengerti cara menggerakan asset mendapat skor 2700 dari 3000 atau jika dalam persentase sebesar 90,00\%. Bedasarkan data yang diperoleh, menurut data interval kelayakan Sugiyono dapat disimpulkan bahwa video sangat bagus dalam memberikan siswa pemahaman.

Aspek kualitas sosial aspek dampak bagi siswa kategori video mempermudah siswa memahami materi diperoleh 25 jawaban ya atau prosentase sebesar 83,33\%. Kualitas teknis mengenai aspek kualitas tampilan kategori kualitas volume suara memperoleh 29 jawaban ya artinya 96,67\% siswa mengatakan suara narator jelas. Untuk kualitas isi aspek ketepatan kategori keterkaitan gambar dengan narasi materi terhadap video tutorial diperoleh 28 jawaban ya. Jadi untuk aspek keterkaitan gambar dengan narasi materi terhadap video tutorial mendapat prosentase sebesar 93,33\%. Untuk kualitas pembelajaran aspek minat siswa kategori ketertarikan siswa terhadap video mendapat 27 siswa mengatakan ya, dengan kata lain $90 \%$ siswa merasa video tutorial menarik. Selanjutnya, pada kualitas isi aspek kelengkapan bagi siswa kategori kejelasan materi memperoleh prosentase jawaban ya sebesar 86,67\%, dengan kata lain 26 siswa merasa materi video tutorial jelas.

Bedasarkan data interval kelayakan Sugiyono, video sangat bagus dalam kualitas social aspek dampak bagi siswa, kualitas teknik aspek kualitas tampilan, kualitas isi aspek ketepatan, kualitas pembelajaran aspek minat dan perhatian, dan kualitas isi aspek kelengkapan.

\subsection{Tabel}

Gambar 3.1 Hasil Pengujian Video Tutorial

\begin{tabular}{|l|l|l|c|c|c|c|}
\hline Kualitas & $\begin{array}{l}\text { Aspek yang } \\
\text { Dinilai }\end{array}$ & \multicolumn{1}{|c|}{ Kategori } & $\begin{array}{l}\text { No. } \\
\text { Soal }\end{array}$ & $\begin{array}{c}\text { Skor } \\
\text { Maksimal }\end{array}$ & $\begin{array}{c}\text { Skor } \\
\text { yang } \\
\text { diperoleh }\end{array}$ & Presentase \\
\hline $\begin{array}{l}\text { Kualitas } \\
\text { sosial }\end{array}$ & $\begin{array}{l}\text { Dampak bagi } \\
\text { siswa }\end{array}$ & $\begin{array}{l}\text { Video } \\
\text { mempermudah } \\
\text { siswa } \\
\text { memahami } \\
\text { materi }\end{array}$ & 1 & 30 & 25 & $83,33 \%$ \\
\hline $\begin{array}{l}\text { Kualitas } \\
\text { teknik }\end{array}$ & $\begin{array}{l}\text { Kualitas } \\
\text { tampilan }\end{array}$ & $\begin{array}{l}\text { Kualitas } \\
\text { volume } \\
\text { suara }\end{array}$ & 2 & 30 & 29 & $96,67 \%$ \\
\hline $\begin{array}{l}\text { Kualitas } \\
\text { isi }\end{array}$ & Ketepatan & $\begin{array}{l}\text { Ketepatan } \\
\text { gambar dan } \\
\text { narasi yang } \\
\text { disampaikan }\end{array}$ & 3 & 30 & 28 & $93,33 \%$ \\
\hline $\begin{array}{l}\text { Kualitas } \\
\text { pembelajaran }\end{array}$ & $\begin{array}{l}\text { Minat dan } \\
\text { perhatian }\end{array}$ & $\begin{array}{l}\text { Ketertarikan } \\
\text { siswa terhadap } \\
\text { video }\end{array}$ & 4 & 30 & 27 & $90 \%$ \\
\hline $\begin{array}{l}\text { Kualitas } \\
\text { isi }\end{array}$ & Kelengkapan & $\begin{array}{l}\text { Kejelasan } \\
\text { uraian } \\
\text { materi }\end{array}$ & 5 & 30 & 26 & $86,67 \%$ \\
\hline
\end{tabular}

\section{Kesimpulan dan Saran}

Dengan adanya video tutorial cara membuat permainan video Turn Based Adventure RPG, siswa SMKN 6 Multimedia akan mendapatkan contoh presentasi yang baik. Siswa kelas 10 juga dapat mengetahui bagaimana cara membuat permainan video Turn Based Adventure RPG sehingga dapat mempersiapkan diri lebih baik ketika terdapat lomba membuat permainan video. Berdasarkan hasil penelitian maka saran yang dapat diberikan adalah diharapkan dalam pengembangan video yang mengajarkan cara membuat permainan video yang berikutnya dapat menjadi lebih baik lagi dengan 
mengajarkan dasar Bahasa C\#. Diharapkan dalam pengembangan video yang berikutnya dapat mengenalkan cara membuat permainan video dengan genre yang lain.

\section{Daftar Pustaka:}

Anas, Muhammad. 2014. Mengenal Metodologi Pembelajaran. Pasuruan: Pustaka Hulwa, pp. 12. Andi Prastowo. 2014. Pengembangan Bahan Ajar Tematik Tinjauan Teoretis dan Praktek. Jakarta, Kencana, pp. 353-354.

Borg. W., R., \& Gall, M., D., G. 1989. Educational Research: An Introduction, Fifth Edition. New York: Longman, pp. 624.

Harjanto. 2008. Perencanaan Pengajaran. Jakarta, Rineka Cipta, pp. 237.

Indriana, Dina. 2011. Various Teaching Media Aids, Jogjakarta: Diva Perss.

Kustandi, Cecep, \& Bambang, S. 2013. Media Pembelajaran Manual dan Digital Edisi Kedua. Bogor: Ghalia Indonesia.

Sugiyono. 2017. Metode Penelitian Bisnis Pendekatan Kuantitatif, Kualitatif, dan $R \& D$, Bandung, Alfabeta, pp. 298-310 